\title{
Effect of exchange transfusion in bilirubin and calcium level in Neonatal Hyperbilirubinemia
}

\author{
Singh $\mathbf{M}^{1}$, Singh $\mathbf{M}^{2}$, Tiwari $\mathrm{S}^{3}$ \\ ${ }^{1}$ Dr Manishi Singh, Department of Biochemistry, Chirayu Medical College and Hospital/ Barkatullah University, M.P. \\ India, ${ }^{2}$ Dr Manika Singh, Department of Oral Medicine and radiology, Mansarovar Dental College/ Barkatullah \\ University, M.P. India, ${ }^{3}$ Dr Surya Tiwari, Department of Biochemistry, Chirayu Medical College and Hospital/ \\ Barkatullah University, MP, India
}

Address for correspondence: Dr Manishi Singh, Email: singhmanishi.singh@ gmail.com

\begin{abstract}
Background: Hyperbilirubinemia is very common and usually benign in the term newborn infant and late preterm infant at 35-36 completed weeks' gestation. Critical hyperbilirubinemia is uncommon but has the potential for causing long term neurological impairment. The present study is designed to determine the effect of exchange transfusion in biochemical parameters in pre-term and full term infants. Methodology: Sixty newborns who underwent double volume exchange transfusion for different indications were studied. The infants were divided into two groups, Group A containing Full term infants and Group B containing Preterm infants. Blood samples were obtained and the following tests were performed i.e. serum bilirubin and blood calcium. Result: A significant decrease in serum bilirubin values was observed in both the groups after exchange transfusion. Also a significant elevation of blood calcium level was found in both the groups of infant studied. Conclusion: Careful monitoring of the risk factors involved a systematic approach to the detection and follow - up of jaundice with the appropriate laboratory investigations, along with judicious exchange transfusion when indicated, are all essential to avoid these complications.
\end{abstract}

Keywords: Hyperbilirubinemia, Jaundice, Pre-Term Newborn, Exchange Transfusion.

\section{Introduction}

Hyperbilirubinemia is the commonest morbidity in the neonatal period and $5-10 \%$ of all newborns require intervention for pathological jaundice. Severe hyperbilirubinemia in relatively healthy term or late preterm newborns (greater than 35 weeks' gestation) continues to carry the potential for complications from acute bilirubin encephalopathy and chronic sequelae. Neonatal hyperbilirubinemia with mild to moderate elevation of serum bilirubin levels is generally considered to be an innocuous state. However, if serum bilirubin levels exceed a dangerous limit, which varies with birth weight, gestational age, chronological age and internal milieu of the body, bilirubin may cross blood brain barrier and bilirubin encephalopathy results. Severe hyperbilirubinemia occurs when the total serum bilirubin (TSB) concentration is $>340 \mu \mathrm{mol} / \mathrm{L}$ at any time during the first 28 days of life and critical hyperbilirubinemia occurs when the TSB concentration

Manuscript received: $4^{\text {th }}$ July 2015

Reviewed: $14^{\text {th }}$ July 2015

Author Corrected: $29^{\text {th }}$ July 2015

Accepted for Publication: $8^{\text {th }}$ Aug 2015 is $>425 \mu \mathrm{mol} / \mathrm{L}$ during the first 28 days of life. It is estimated that $60 \%$ of the term newborns develop jaundice and $2 \%$ reach a TSB concentration $>340$ $\mu \mathrm{mol} / \mathrm{L}$ [1]. Several risk factors have been identified for the development of severe hyperbilirubinemia in the newborns. These risk factors are all common and the attributable risk of each is therefore very low.

Risk factors for the development of severe hyperbilirubinemia

- Jaundice observed in the first 24 hours.

- Blood group incompatibility with positive direct antiglobulin test, other known hemolytic disease (e.g.: G6PD deficiency).

- Gestational age 35-36 week.

- Previous sibling received phototherapy.

- Cephalohematoma or significant bruising.

- If breast feeding is not going well and weight loss is excessive. 
Despite advent of phototherapy as a therapeutic modality, Exchange Transfusion (ET) plays a significant role in the treatment of neonatal hyperbilirubinemia by eliminating serum bilirubin quickly. In ET infant's blood is exchanged with adult blood by conventational discontinuation technique in 10 $\mathrm{ml}$ aliquots. Total volume of donor's blood infused is usually double $(170 \mathrm{ml} / \mathrm{kg}$ body weight $)$ the total volume of Infant ( $85 \mathrm{ml} / \mathrm{kg}$ body weight) and it replaces about $87 \%$ of the infant's blood. A significant proportion of serum bilirubin is removed from the body which ensures immediate protection against the imminent bilirubin toxicity [2]. Exchange transfusion of blood collected with acid citrate dextrose (ACD) may produce calcium abnormalities [3]. To decrease the morbidity from chelation of divalent cations by citrate, injection of calcium gluconate during exchange transfusion was advocated [4].

\section{An exchange transfusion soon after birth is indicated if:}

1. Cord bilirubin is $\geq 5 \mathrm{mg} / \mathrm{dl}$

2. Cord $\mathrm{Hb}$ is $\leq 10 \mathrm{mg} / \mathrm{dl}, \mathrm{PCV}<30$.

3. Previous sibling history and positive DCT

\section{Subsequent exchange transfusion is indicated if:}

1. Bilirubin $\geq 10 \mathrm{mg} / \mathrm{dl}$ within 24 hours of age.

2. Bilirubin $\geq 15 \mathrm{mg} / \mathrm{dl}$ between $25-48$ hours of age.

3. Bilirubin $\geq 20 \mathrm{mg} / \mathrm{dl}$ after 48 hours of age.

4. Rate of rise of bilirubin is $\geq 0.5 \mathrm{mg} / \mathrm{dl} / \mathrm{hr}$.

Although ET is considered to be a safe undertaking, many changes takes place in various serum biochemical parameters, plasma osmolality and electrolyte profile in the recipient infants which may give rise to postoperative complications including death, syncope and serious ECG changes [2, 4-7]. The most commonly reported adverse incidents during or soon after exchange transfusion: Hypo or hyperglycemia, hypocalcaemia, acidemia, arrhythmias, bradycardia, neutropenia, septicemia, Hypo or Hyperthermia [8].

\section{Material and Method}

The present work was done in the Department of Biochemistry in association with the Department of Pediatrics in Gandhi Medical College Bhopal. 60 Newborn infants of both sexes with hyperbilirubinemia who underwent ET for any reason in neonatal unit were selected for the study and were divided in two groups for the study.

Group A: Term, healthy newborns who were appropriate for gestational age and were admitted solely for asymptomatic hyperbilirubinemia.

Group B: Preterm newborns who had primary additional medical risk factors prior to exchange transfusion, i.e., ill newborns.

Complete history of pregnancy and delivery was elicited, birth weight of babies were recorded, complete examination of the babies was carried out regarding extent of jaundice, condition of body, cephalhematoma, etc.

ET was performed by ACD blood using standard method through umbilical route in NICU under strict aseptic precautions. Blood samples were collected before exchange and after exchange through the umbilical catheter after 5 minutes. Samples were collected in clean plain vial for serum bilirubin and serum calcium estimation. Serum bilirubin was estimated by Jendrassik colorimetric method. Serum calcium was done by OCPC method. Pre and Post Exchange values of the above described biochemical parameters were analyzed statistically applying the student's paired t-test.

\section{Results}


Table 1: Clinical details of Group A \& B Infants studied

\begin{tabular}{|c|c|c|c|c|c|c|}
\hline & \multicolumn{2}{|c|}{ Number and sex } & \multicolumn{2}{|c|}{ Birth weight (grams) } & \multicolumn{2}{|c|}{ Gestational age } \\
\hline & Male & Female & Range & No. Of infants & Weeks & Number \\
\hline \multirow[t]{2}{*}{ Term infants } & \multirow{2}{*}{16} & \multirow{2}{*}{8} & $2500-2999$ & 15 & & \\
\hline & & & $3000-3499$ & 9 & & \\
\hline \multirow{5}{*}{ Premature infants } & \multirow{5}{*}{20} & \multirow{5}{*}{16} & $\begin{array}{l}<1000 \text { gm. } \\
\text { (up to } 999 \mathrm{gms} \text { ) }\end{array}$ & 0 & ---- & ---- \\
\hline & & & 1000-1499 gms. & 6 & $<28$ wks & 0 \\
\hline & & & 1500-1999 gms. & 17 & $28-31$ & 5 \\
\hline & & & 2000-2499 gms. & 9 & $32-36$ & 19 \\
\hline & & & $>2500 \mathrm{gms}$. & 4 & $37-41$ & 12 \\
\hline
\end{tabular}

Table 1 shows the clinical details of term (Group A) and preterm (Group B) infants studied. Table 2 shows the etiology of jaundice in both Group A and Group B infants studied.

Table 2: Distribution of Newborns according to etiology of jaundice

\begin{tabular}{|l|l|l|l|}
\hline S.No. & Etiology & Group A $(\mathbf{n}=\mathbf{2 4})$ & Group B $(\mathbf{n}=\mathbf{3 6})$ \\
\hline 1 & Rh incompatibility & 5 & 4 \\
\hline 2 & ABO incompatibility & 9 & 10 \\
\hline 3 & Rh and ABO incompatibility & 2 & 4 \\
\hline 4 & G6PD deficiency & 0 & 2 \\
\hline 5 & Cephalhematoma & 0 & 2 \\
\hline 6 & Unidentified & 8 & 9 \\
\hline
\end{tabular}

Table 3: Pre and Post Exchange Serum Bilirubin and calcium changes

\begin{tabular}{|l|l|l|}
\hline \multirow{2}{*}{ Groups } & Serum Bilirubin levels $(\mathbf{m g} / \mathbf{d l})$ & \multirow{3}{*}{ 'p' value } \\
\cline { 2 - 2 } & $\begin{array}{l}\text { Pre Exchange and Post Exchange Difference } \\
\text { (Mean } \pm \text { SD) }\end{array}$ & \\
\hline Group A & $8.51 \pm 9.61$ & $<0.001$ \\
\hline Group B & $8.86 \pm 10.89$ & $<0.001$ \\
\hline Groups & Serum Calcium levels $(\mathbf{m g} / \mathbf{d l})$ & 'P' Value \\
\hline & $\begin{array}{l}\text { Pre Exchange and Post exchange Difference } \\
\text { (Mean } \pm \text { SD) }\end{array}$ & \\
\hline Group A & $1.495 \pm 1.86$ & $<0.001$ \\
\hline Group B & $2.62 \pm 2.93$ & $<0.001$ \\
\hline
\end{tabular}

Highly significant $(\mathrm{p}<0.001)$ difference was observed in serum bilirubin level after Post Exchange transfusion in both the group of infants studied. In the present study mean Post Exchange total calcium level was significantly higher than the pre exchange total calcium level $(\mathrm{p}<0.001)$ in both the groups of infants studied (Table 3 ).

\section{Discussion}

Jaundice in the newborn is one of the most frequently encountered clinical problems in the neonatal period. This is the most common cause of deafness and mental retardation in children.

Exchange transfusion is the most reliable and rapid method of removing bilirubin from the body. The classical controlled clinical trial reported by Mollison and Walker [9] and subsequent clinical experience has established exchange transfusion as the standard treatment for preventing bilirubin encephalopathy in severe neonatal hyperbilirubinemia. 
In the present study, out of 60 newborns, 64\% (32) were low birth weight. 23 newborns were preterm while 9 newborns were full term (SGA). In group A, $62.58 \%$ newborns had their birth weights in the range of 25002999 grams, while only $37.5 \%$ were $>3000$ grams. All newborns in group A were term (37-41 weeks). In group B of ill newborns, maximum $47.22 \%$ newborns had their birth weight in the range of 1500-1999 grams and $25 \%$ in the range of 2000-2499 grams. Maximum newborns $(52.77 \%)$ were between $32-36$ weeks of gestational age.

Increased incidence of neonatal hyperbilirubinemia in preterm and low birth weight babies can be explained on the basis of hepatic immaturity, increased bilirubin load, decreased synthesis of ligandin (Y protein) and decreased UDPG (T) activity.

Our study found that maximum number of newborns who were exchanged for jaundice had ABO incompatibility i.e. $37.5 \%$ in group $\mathrm{A}$ and $27.27 \%$ in group B. Rh incompatibility was present in $20.9 \%$ newborns in group A and $11.11 \%$ newborns in group B. In the present study the ratio of ABO: Rh HDN is $2: 1$. The present findings are in accordance with the study of Das et.al [10], Devarajan Verma M. et al. [11], M.R. Lokeshwar and Minaxi Mehta. In the present study, G6PD deficiency and Cephalhematoma were documented as the cause of jaundice in $5.55 \%$ newborns each. This is also reported by Kaplan, M. et al. [12], Deshmukh et.al, Bajpai et.al [13]. In 50\% cases the etiology of jaundice could not be determined. The present findings are in accordance with the study of Merchant and Abhyankar [14], Jackson J.C [15].

In the present study we found that in group A, 54.1\% (13) newborns had their pre exchange bilirubin levels in the range of $20-25 \mathrm{mg} / \mathrm{dl}$ and in group B, $27.7 \%$ (11) newborns had their serum bilirubin levels in the range of $16-19 \mathrm{mg} / \mathrm{dl}$. To avoid the risk of bilirubin encephalopathy in group B, keeping in view their clinical status, the exchange transfusion was undertaken even at lower levels of serum bilirubin. The drop in serum bilirubin levels following exchange transfusion, when expressed as a percentage in relation to pre exchange serum bilirubin was $61 \%$ and $53 \%$ in Group A and Group B respectively $(\mathrm{p}<0.001)$. So, exchange transfusion as a modality of treatment was equally effective in healthy as well as ill newborns. The present findings are in accordance with the study of Merchant and Abhyankar [14], Zuelzer and Robinson [16, 17] suggested on extra vascular bilirubin pool equilibrating with the plasma pool. The total clearance of bilirubin by an exchange is the result of two simultaneous processes, the rate of removal from the plasma and the rate of equilibration between the plasma and the extravascular pool.

In the present study mean Post Exchange total calcium level was significantly higher than the pre-exchange total calcium level $(\mathrm{p}<0.001)$ in both the groups of infants studied. This transient rise of total calcium level was associated with routine use of intravenous administration of $10 \%$ calcium gluconate after each $100 \mathrm{ml}$ of blood exchange in order to counteract any fall in serum ionized calcium levels [18]. Such fall occurs due to calcium chelating properties of citrate which is present in high concentration in the donor's blood where it is used as an anticoagulant $[19,20]$. Calcium level came within the normal range after 24 hours of exchange.

\section{Conclusion}

Kernicterus is still occurring but should be largely preventable if health care personnel follow the recommendations listed in this guideline. These recommendations emphasize the importance of universal, systematic assessment for the risk of severe hyperbilirubinemia, close follow-up, and prompt intervention, when necessary. Careful monitoring of the risk factors involved a systematic approach to the detection and follow-up of jaundice with the appropriate laboratory investigations, along with judicious exchange transfusion when indicated, are all essential to avoid these complications.

\section{Funding: Nil \\ Conflict of interest: Nil \\ Permission from IRB: Yes}

\section{References}

1. Stevenson DK, Fanaroff AA, Maisels MJ, et al. Prediction of hyperbilirubinemia in near term and term infants. Pediatrics. 2001 Jul;108(1):31-9.

2. Cloherty, J.P. and Stark, P.A.: Manual of neonatal care, $33^{\text {rd }}$ Ed. Little Brown and Co. 1982.

3. Farquhar JW, Smith H: Clinical and biochemical changes during exchange transfusion. Arch Dis Child. 1958 Apr;33(168):142-59. 
4. Sherman I, Alperstein BB, Sherman BK: Intravenous calcium gluconate as aid in reduction of post transfusion reaction. N Y State J Med 43:2419, 1943.

5. Boggs TR, Westphal MC. Mortality of exchange transfusion. Pediatrics 1960;26 (5): 745-755.

6. Aylor WC. Mortality and Morbidity of exchange transfusion. Can Med Assoc J. 1962 Dec 15;87(24):1267-70.

7. Jablonski WJ: Risks associated with exchange Transfusion. N Engl J Med. 1962 Jan 25;266:155-60..

8. Milner RD, Fekete M, Assan R. Glucagon, Insulin and growth hormone response to exchange transfusion in premature and term infants. Arch Dis Child. 1972 Apr;47(252):186-9.

9. Mollison PL, Walker W. Controlled trials of the treatment of Hemolytic disease of the newborn. Lancet. 1952 Mar 1;1(6705):429-33.

10. Das, B.N.O. et al., Neonatal Hyperbilirubinemia associated with G6PD- a preliminary study Indian Pediatr 1974; 9: 10.

11. Verma M, Chhatwal J, Singh D. Neonatal Hyperbilirubinemia. Indian J Pediatr. 1988 NovDec;55(6):899-904.

12. Kaplan M, Beutler E, Vreman HJ et al. Neonatal hyperbilirubinemia in G6PD deficient heterozygotes. Pediatrics. 1999 Jul;104(1 Pt 1):68-74.
13. Bajpai PC, Sugden D, Stern L, Denton RL. Serum ionic magnesium in exchange transfusionJ Pediatr. 1967 Feb;70(2):193-9.

14. Merchant RH, Abhyankar SH. Exchange Transfusion in newborns- An analysis of 100 cases. Indian Pediatr. 1985 May;22(5):349-53.

15. Jackson JC. Adverse events associated with exchange transfusion in healthy and Ill newborns. Pediatrics. 1997 May;99(5):E7.

16. Zuelzer, W., Brown A.: Neonatal Jaundice. A review. Am J Dis Child. 1961 Jan;101:87-127.

17. Zuelzer WW, Brown AK. Studies in hyperbilirubinemia II. Clearance of bilirubin from plasma and extravascular space in newborn infants during exchange transfusion. AMA J Dis Child. 1957 Mar;93(3):274-86.

18. Wexler IB, Pincus JB, Natelson S, Lugovoy JK. The fate of citrate in erythroblastic infants treated with exchange transfusion. J Clin Invest. 1949 May;28(3):474-81.

19. Radde IC, Parkinson DK, Höffken B, Appiah KE, Hanley WB. Calcium ion activity in the sick neonates: Effect of bicarbonate administration and exchange transfusion. Pediatr Res. 1972 Jan;6(1):43-9.

20. Gershanik JJ, Levkoff AH, Duncan R. Serum ionized calcium values in relation to exchange transfusion. J Pediatr. 1973 May;82(5):847-50.

\section{How to cite this article?}

Singh M, Singh M, Tiwari S. Effect of exchange transfusion in bilirubin and calcium level in Neonatal Hyperbilirubinemia. Int J Med Res Rev 2015;3(7):733-737. doi: 10.17511/ijmrr.2015.i7.138. 